\title{
An update on MSA: premotor and non-motor features open a window of opportunities for early diagnosis and intervention
}

\author{
Viorica Chelban ${ }^{1,2}$. Daniela Catereniuc ${ }^{2,3,4}$. Daniela Aftene ${ }^{3,4} \cdot$ Alexandru Gasnas $^{3,4,5}$. Ekawat Vichayanrat ${ }^{6}$. \\ Valeria lodice $^{6} \cdot$ Stanislav Groppa ${ }^{2,3,4} \cdot$ Henry Houlden ${ }^{1,7}$
}

Received: 8 March 2020 / Revised: 29 April 2020 / Accepted: 30 April 2020 / Published online: 20 May 2020

(c) The Author(s) 2020

\begin{abstract}
In this review, we describe the wide clinical spectrum of features that can be seen in multiple system atrophy (MSA) with a focus on the premotor phase and the non-motor symptoms providing an up-to-date overview of the current understanding in this fast-growing field. First, we highlight the non-motor features at disease onset when MSA can be indistinguishable from pure autonomic failure or other chronic neurodegenerative conditions. We describe the progression of clinical features to aid the diagnosis of MSA early in the disease course. We go on to describe the levels of diagnostic certainty and we discuss MSA subtypes that do not fit into the current diagnostic criteria, highlighting the complexity of the disease as well as the need for revised diagnostic tools. Second, we describe the pathology, clinical description, and investigations of cardiovascular autonomic failure, urogenital and sexual dysfunction, orthostatic hypotension, and respiratory and REM-sleep behavior disorders, which may precede the motor presentation by months or years. Their presence at presentation, even in the absence of ataxia and parkinsonism, should be regarded as highly suggestive of the premotor phase of MSA. Finally, we discuss how the recognition of the broader spectrum of clinical features of MSA and especially the non-motor features at disease onset represent a window of opportunity for disease-modifying interventions.
\end{abstract}

Keywords Multiple system atrophy $\cdot$ Non-motor features $\cdot$ Premotor phase $\cdot$ MSA

Viorica Chelban

v.chelban@ucl.ac.uk

1 Department of Neuromuscular Diseases, Queen Square Institute of Neurology, University College London, London WC1N 3BG, UK

2 Neurobiology and Medical Genetics Laboratory, "Nicolae Testemitanu" State University of Medicine and Pharmacy, 165, Stefan cel Mare si Sfant Boulevard, 2004 Chişinău, Republic of Moldova

3 Department of Neurology, Epileptology and Internal Diseases, Institute of Emergency Medicine, 1, Toma Ciorba Street, 2004 Chişinău, Republic of Moldova

4 Department of Neurology nr. 2, Nicolae Testemitanu" State University of Medicine and Pharmacy, 165, Stefan cel Mare si Sfant Boulevard, 2004 Chişinău, Republic of Moldova

5 Cerebrovascular Diseases and Epilepsy Laboratory, Institute of Emergency Medicine, 1, Toma Ciorba Street, 2004 Chişinău, Republic of Moldova

6 Autonomic Unit, National Hospital for Neurology and Neurosurgery, UCL NHS Trust, London WC1N 3BG, $\mathrm{UK}$

7 Neurogenetics Laboratory, National Hospital for Neurology and Neurosurgery, Queen Square, London WC1N 3BG, UK

\section{Introduction}

Multiple system atrophy (MSA) is a sporadic, adult-onset, progressive, rare neurodegenerative disorder of uncertain etiology. It manifests with diverse clinical features, characterized mainly by a combination of parkinsonism with a poor response to levodopa treatment, cerebellar features, and autonomic failure. The definite diagnosis of MSA can still only be established pathologically with the presence of glial cytoplasmic inclusions (GCI) at postmortem [1-3].

In the past, a variety of terms were used to describe MSA. In 1900, Joseph Jules Dejerine and André Thomas first reported two cases presenting with cerebellar ataxia and pathological lesions in the cerebellum and brainstem, described as olivopontocerebellar atrophy. Sixty years later, Shy and Drager described two patients with parkinsonism and autonomic symptoms including orthostatic hypotension [4] and Van der Eecken et al. reported cases with parkinsonism and striatonigral degeneration at autopsy in the same year. The term 'MSA' was first introduced in 1969 by Graham and Oppenheimer to represent 
all three neurological entities: olivopontocerebellar atrophy (OPCA), the Shy-Drager syndrome, and striatonigral degeneration (SND) [5]. Papp et al. first demonstrated the presence of argyrophilic glial cytoplasmic inclusions in the central nervous system of patients diagnosed with MSA in 1989 [6]. These inclusions were later reported to be positive for $\alpha$-synuclein, and nowadays, alpha-synuclein inclusions in oligodendroglia are the recognized neuropathologic hallmarks of MSA and may even represent a primary pathologic event [7]. Together, Parkinson's disease, dementia with Lewy bodies, and MSA are called $\alpha$-synucleinopathies [8]. The mechanisms by which $\alpha$-synuclein, a neuronal protein, ends up in the oligodendroglia causing pathology in MSA remain unclear. There is growing evidence that oligodendroglial pathology and "prion-like" spreading of misfolded $\alpha$-synuclein may be the primary events in MSA leading to neurodegeneration [7-9]. In addition, proteasomal and mitochondrial dysfunction [10], dysregulation of myelin lipids [11, 12], genetic factors [13], microglial activation [14], neuroinflammation [15], proteolytic disturbance, autophagy [16], and other factors contributing to oxidative stress [17] have been reported as part of the pathogenesis of MSA.

MSA is an orphan disease [18] with an estimated incidence of $0.6-3$ per 100,000 people $[19,20]$. The incidence increases with age reaching 12/100,000 in those aged over 70 [21], with no difference between men and women [22, 23]. Prevalence estimates range from 1.9 to 4.9 [24] and may reach up to 7.8 per 100,000 after the age of 40 [20, 22, 23].

Given its varied clinical manifestation, MSA is frequently misdiagnosed, especially at disease onset. An autonomic presentation of MSA can be indistinguishable from pure autonomic failure (PAF). PAF is currently considered an idiopathic, sporadic, rare neurodegenerative disorder characterized by autonomic failure without other neurological symptoms or signs [25]. Recently, PAF has received more attention from researchers, partly due to shared common features with other forms of synucleinopathy. Furthermore, recent studies show that a significant proportion of patients with PAF eventually develop DLB, PD, or MSA over time. There are certain features that could predict these conversions [26, 27] raising the question of whether PAF is indeed a distinct disease entity or simply a prodromal disease stage of alpha-synucleinopathies.

A patient presenting with parkinsonism with autonomic involvement may be misdiagnosed as suffering from Parkinson's disease. Ataxias resulting from diverse etiologies such as toxins, immune-mediated, or genetic forms-for example fragile $\mathrm{X}$-associated tremor ataxia syndrome, spinocerebellar ataxia (especially type 6), or late-onset Friedreich's ataxia [2] — can all mimic the cerebellar MSA phenotype. False-positive MSA diagnoses are also frequent. About
$20 \%$ of cases diagnosed in life as MSA subsequently have a pathology confirming PD or DLB [28].

MSA is characterized by worsening of motor and nonmotor features over an average of 10 years, with a fast progression from disease onset, helping to distinguish it from similar degenerative conditions, described above [29]. Approximately $50 \%$ of patients require walking aids within 3 years from the onset of motor symptoms [30]; $60 \%$ require a wheelchair after 5 years [31] with a median time to becoming bedridden of 6-8 years [30]. However, a more benign MSA variant with longer survival of over 15 years has been reported in pathology-confirmed cases [[2, 32], as well as an aggressive MSA phenotype, with a very short disease duration of less than 3 years [33]. Older age at onset [30,31, 34-36], a parkinsonian phenotype [29, 35], early development of severe autonomic failure [30, 35, 37, 38], and severe urinary retention and nocturnal stridor $[39,40]$ are all negative prognostic factors, whereas a cerebellar phenotype [34] and later onset of autonomic failure [32] predict slower disease progression. Bronchopneumonia, urosepsis, and sudden death are the main causes of death in MSA. Sudden death, which often occurs at night, is thought to result from either acute bilateral vocal-cord paralysis or acute disruption of the brainstem cardiorespiratory drive.

Striatonigral degeneration (SND) and olivopontocerebellar atrophy (OPCA) are pathological subtypes of MSA. Four levels of pathological severity have been described on autopsy of MSA brains. The typical $\alpha$-synuclein immunoreactive inclusion pathology (GCIs) within oligodendrocytes [41] are at the most severe end and are required for a definite postmortem diagnosis of MSA. Less frequent are neuronal cytoplasmic (NCI) and neuronal nuclear inclusions (NNI), glial nuclear (GNI), astroglial cytoplasmic inclusions, and neuronal threads, also composed of $\alpha$-synuclein. The next level of severity is characterized by selective neuronal loss and axonal degeneration involving multiple regions of the nervous system with predominant involvement of the striatonigral and OPC systems, followed by myelin degeneration with pallor and reduction in myelin basic protein (MBP), with accompanying astrogliosis. The final and most mild form of pathology is microglial activation alone [17].

Glial cytoplasmic inclusions (GCIs) and the resulting neurodegeneration commonly occur across multiple CNS sites. In addition to the striatonigral and OPC involvement, CGIs are found in the autonomic nuclei of the brainstem [locus coeruleus (LC), nucleus raphe, dorsal vagal nuclei, etc.], spinal cord, sacral visceral pathways [42], and the peripheral nervous system [43], defining MSA as a truly multi-system disease [7].

Currently, MSA is considered an oligodendrogliopathy with a secondary neuronal involvement. Both a reactivation of $\alpha$-syn gene (SNCA) [44] hypothesis and an uptake from neurons or from the extracellular environment [45, 
46] have been proposed. A prion-like mechanism of propagation in MSA [47, 48] predicts the existence of "strains" with defined incubation times and patterns of neuropathology. Strains of alpha-synuclein (fibrils and ribbons) represent different conformational polymorphs of the protein. The existence of different alpha-synuclein strains may be related to different phenotypes. For example, fibrillar $\alpha$-syn polymorphisms underlies different propagation patterns of $\alpha$-syn pathology [49], while $\alpha$-synuclein in glial cytoplasmic inclusions (GCI- $\alpha$-Syn) forms more compact and about 1,000 -fold more potent structures than Lewy bodies- $\alpha$-Syn in seeding $\alpha$-Syn aggregation, consistent with the highly aggressive MSA [50]. Also, it has been shown that oligodendrocytes, and not neurons, transform misfolded $\alpha$-Syn into a GCI-like strain, emphasizing the fact that different intracellular milieus generate distinct $\alpha$-Syn strains and the GCI- $\alpha$-Syn maintains its high seeding activity when propagated in neurons.

The diagnostic criteria for MSA define three levels of certainty: possible, probable, and definite MSA [3] (Table 1). However, a widening range of pathological and clinical presentations have been described in MSA, including several subtypes of MSA that do not fit into the current classification (Table 2) [51].

Based on the predominant clinical phenotype, MSA is categorized into MSA-P when parkinsonism is predominant and is associated with SND, and MSA-C, with OPCA, when associated with dominant cerebellar features. The combination of both forms, "mixed" MSA, also exists [3]. In Asian populations, the majority of MSA cases-about $70-80 \%$ [52] - are of MSA-C type, whereas in the Caucasian population, MSA-P type predominates (about 67-84\%) [29, 53]. MSA-P is characterized by parkinsonism with rigidity, postural instability with a tendency to fall, and poor response to levodopa [54]. The motor symptoms are usually symmetrical [55]. Rest tremor is rare, whereas irregular postural and action tremor may occur [57]. MSA-C is associated with cerebellar ataxia affecting arms, legs, action tremor, downbeat nystagmus, and hypometric saccades [56]. Hyperreflexia and Babinski sign may occur in $30-50 \%$ of patients, while abnormal postures, such as bent spine, antecollis, and hand or foot dystonia, are rare [56]. Dysphonia, repeated falls, drooling, dysphagia, dystonia, and pain occur in advanced stages of the disease [57]. Spinal myoclonus in MSA-C caused by $\alpha$-synuclein deposition in the spinal cord has also been reported [58].

The onset of motor symptoms is on average around 56 years of age ( \pm 9 years), with both sexes equally affected [59]. However, up to $75 \%$ of MSA cases have a prodromal phase with non-motor symptoms, such as cardiovascular autonomic failure, orthostatic hypotension, urogenital and sexual dysfunction, REM-sleep behavior disorder, and respiratory disorders. These may precede the motor presentation by months to years [60]. Furthermore, up to $95 \%$ of MSA patients experience non-motor symptoms at some point during the course of the disease with autonomic failure, in particular urogenital (urinary incontinence and impaired detrusor muscle contractibility) and cardiovascular symptoms being frequent and early features of MSA [61].

In this review, we describe this wide clinical spectrum of features now seen in MSA with a focus on the non-motor symptoms and the premotor phase, and provide an up-todate overview of the current understanding in this fastgrowing field.

\section{The neuropathology of non-motor features in MSA}

The distribution of neurodegenerative changes in patients with MSA is broadly reflected by $\alpha$-synuclein-positive oligodendroglial cytoplasmic inclusions [2]. During the course of the disease, most patients present with a combination of gastrointestinal, cardiovascular, urogenital, or thermoregulatory abnormalities of different severities [2, 36]. Several brain regions of MSA patients are severely depleted of dopamine and norepinephrine including the corpus striatum, nucleus accumbens, substantia nigra, locus coeruleus, hypothalamus, and septal nuclei [62]. A severe loss of A5 noradrenergic neurons in the pontine tegmentum has been shown in MSA, leading to respiratory and cardiovascular manifestations, along with similar severe losses of noradrenergic neurons in the locus ceruleus $[63,64]$. The loss of C1-group neurons (neurons that synthesize epinephrine) contributes to orthostatic hypotension in MSA, with the severity of neuronal loss in MSA being greater than in PD and DLB [65, 66]. Impaired reflex release of vasopressin in response to hypotension or hypovolemia in MSA may be a consequence of degeneration of noradrenergic projections to the magnocellular vasopressin neurons from A1 neurons, localized in the caudal ventrolateral medulla $[65,67]$. Reduced orexin immunoreactivity, likely associated with sleep apnea syndrome, has been observed in the nucleus basalis of Meynert in MSA patients [68]. Tyrosine hydroxylase neuronal loss in the periaqueductal gray of MSA, similar to Lewy body disease, has also been reported [69].

Involvement of the insular cortex has been related to nonmotor symptoms in MSA, including autonomic dysfunction and arousal [70]. Activation of the subgenual and pregenual portions has been associated with cardiovagal responses in normal people; activation of the dorsal anterior cingulate cortex (the midcingulate cortex), part of the salience network, has been shown to be associated with sympathetic activation related to behavioral arousal [71].

The brainstem regions, in particular those where the respiratory centers are located, are frequently affected in MSA. 


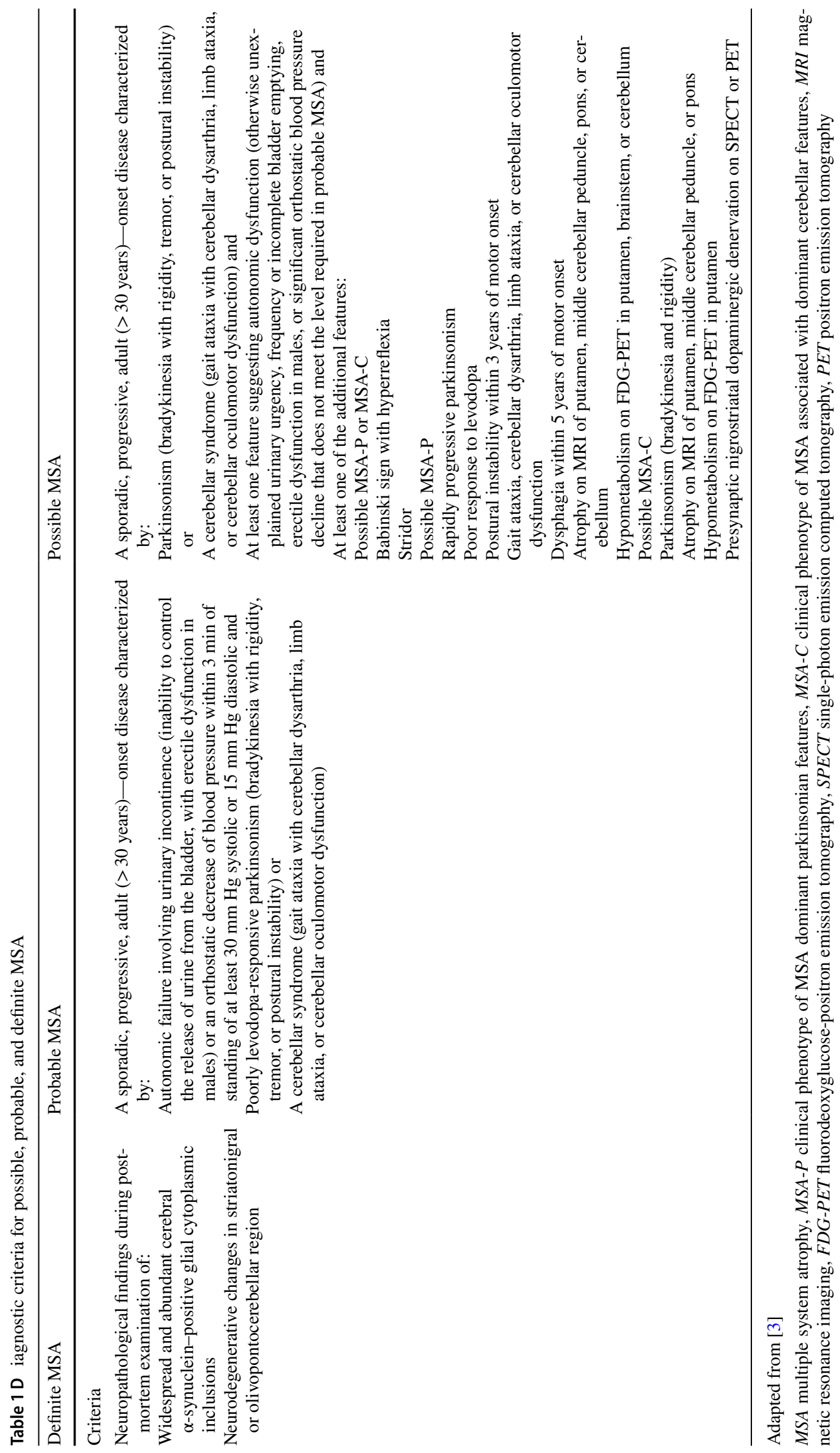


Table 2 Subtypes of MSA that do not fulfill current diagnostic criteria

\begin{tabular}{ll}
\hline Type & Description \\
\hline MSA with mixed pathology & $\begin{array}{c}\text { Abundant } \alpha \text {-synuclein inclusions, identified as frontotemporal lobe degeneration with } \alpha \text {-synuclein (FTLD- } \\
\text { synuclein) in the presence of SND and variable OPC degeneration, but in the absence of autonomic dysfunc- } \\
\text { tion [205]. Clinical features are typically consistent with frontotemporal dementia and a progressive non-fluent } \\
\text { aphasia with no autonomic dysfunction }\end{array}$ \\
A non-motor variant of pathologically confirmed MSA showing neither parkinsonism nor cerebellar symptoms \\
Non-motor variant MSA \\
[195]. The case presented clinically with 10-year history of autonomic failure (orthostatic hypotension and neu- \\
rogenic bladder), RBD and a 2-year history of stridor prior to sudden death \\
Described as cases with prolonged survival up to 15 years or more in 2-3\% of MSA patients [152]. Most of them \\
showed a slowly progressing parkinsonism resembling PD in the first 10 years of disease with subsequent rapid \\
deterioration after the development of autonomic failure, before which a correct diagnosis was difficult. Many of \\
these patients developed motor fluctuations and levodopa-induced choreiform dyskinesias leading to considera- \\
tion of deep brain stimulation, which is a procedure currently not recommended for MSA patients [199]. These \\
rare, long-surviving patients with MSA-P, were considered "benign" forms [32]. Pathological examination of \\
patients with survival longer than 18 years has revealed an extensive distribution of GCIs in the CNS [206] \\
The presence of GCIs may represent an age-related phenomenon not necessarily processing to overt clinical dis- \\
ease similar to incidental Lewy body disease [207] \\
A rare aggressive form with GCIs and neurodegeneration was almost completely restricted to the SN and putamen, \\
thus representing "pure" SND [208]
\end{tabular}

FTLD synuclein-frontotemporal lobar degeneration, $S N D$ striatonigral degeneration, $O P C$ olivopontocerebellar, RBD REM sleep behavior disorder, $P D$ Parkinson disease, $M S A$ multiple system atrophy, MSA-P clinical phenotype of MSA dominant parkinsonian features, $G C I s$ glial cytoplasmic inclusions, $C N S$ central nervous system, $S N D$ striatonigral degeneration

The ventral medullary arcuate nucleus, likely responsible for respiratory chemosensitivity, degenerates in MSA [72]. In addition, the pre-Botzinger complex of the medulla and the neurokinin-1 immunoreactive neurons, responsible for respiratory rhythmogenesis, are similarly markedly affected $[73,74]$. The neuronal loss in MSA, from the dorsal motor nucleus of the vagus (DMV), located in the dorsomedial medulla [75], may contribute to baroreflex-triggered cardioinhibition and a respiratory sinus arrhythmia [76].

REM-sleep behavior disorder (RBD) is commonly seen in this disease and may relate to pathology affecting the pontomedullary brainstem nuclei in MSA [77, 78]. During REM sleep, atonia is controlled by the pontomedullary structures [the magnocellular reticular formation (MCRF), sublaterodorsal (SLD), and pedunculopontine and laterodorsal (PPN/ LDT) nuclei] [77]. Elimination of atonia during REM sleep, caused by lesions in SLD/SC and MCRF (even unilaterally), likely leads to dream enacting behavior [79]. Depletion of cholinergic neurons in the PPN/LDN complex has been shown in autopsy studies of patients with MSA [80]. PPN may have a modulatory role in REM-related phenomena rather than a primary role for the atonia during REM sleep [75].

Preganglionic and postganglionic sudomotor denervation probably underlies the anhidrosis seen in MSA, with more postganglionic dysfunction seen later in the disease [76]. Postganglionic cardiac sympathetic denervation also has been shown to occur in a minority of cases of MSA[81\}. The preganglionic neurons innervating the detrusor muscle
[82] and loss of neurons of the Onuf nucleus innervating the sphincter are related to early and severe bladder dysfunction.

\section{Clinical manifestations of non-motor features}

\section{Cardiovascular failure in MSA}

\section{Orthostatic hypotension}

Early symptoms in MSA are frequently related to cardiovascular and autonomic failure and precede motor manifestations. In a recent study, the majority of MSA patients (77\%) recalled the early autonomic symptoms, initially not recognized as being a manifestation of a neurodegenerative disease [83].

Criteria for diagnosis of probable MSA according to Gilman et al. [3, 84] involve autonomic dysfunction including urinary incontinence (inability to control the release of urine from the bladder, with erectile dysfunction in males) or orthostatic hypotension $(\mathrm{OH})$ (decrease of blood pressure within $3 \mathrm{~min}$ of standing by at least $30 \mathrm{mmHg}$ systolic or $15 \mathrm{mmHg}$ diastolic).

Importantly, autonomic dysfunction may be the only presenting feature in some MSA patients [85]. Symptomatic $\mathrm{OH}$, the main symptom of cardiovascular autonomic failure, often manifests as recurrent syncope, dizziness, nausea, headache, and weakness, and has been reported in $43-81 \%$ of all MSA patients [86, 87]. Cardiovascular autonomic 
failure associated with degeneration of the nucleus ambiguus has been reproduced in an MSA mouse model [88].

An important differential for the autonomic failure in the early stage of MSA is the diagnosis of pure autonomic failure (PAF). Orthostatic hypotension $(\mathrm{OH})$ and its related symptoms, such as light-headedness or dizziness, and sudomotor dysfunction, are the most common presenting feature in PAF [89-91]. Bladder symptoms are also present in some PAF patients, but these features are less severe than in MSA [92]. While respiratory symptoms such as stridor or sighing are common in MSA, these symptoms were not reported in patients with PAF [93]. There are only a few studies that have reported pathology in patients with PAF. Intracytoplasmic eosinophilic inclusions with Lewy bodies resembling those in PD patients were reported in the neurons in autonomic ganglia and postganglionic nerves [91]. Although typical PAF patients have no parkinsonian features, Lewy body deposition in the substantia nigra, locus coeruleus, thoracolumbar, and sacral spinal cord with limited neuronal loss has been described in a case report [90]. Later, pathologically confirmed studies also demonstrated pre- and postganglionic autonomic lesions in PAF patients [91, 94]. These findings suggest that PAF is a limited and peripheral form of alpha-synucleinopathy, in contrast to more central forms in PD and DLB [95].

PAF patients have hyposmia, reduced cardiac MIBG reuptake, and Lewy body deposition both in the skin and central nervous system, similar to PD [96-99]. There is increasing awareness of the progression of patients with the PAF phenotype to other alpha-synucleinopathies. In one study, within 4 years of onset, $34 \%$ of patients with PAF phenoconverted to a manifest CNS alpha-synucleinopathy, either DLB (18\%), PD (8\%), or MSA (8\%). The prognostic implications of autonomic failure are unknown and predictors of phenoconversion to MSA have yet to be determined $[27,100]$. However, it took on average 5 years for patients with PAF to develop motor deficits leading to the diagnosis of MSA, and nearly twice as long (9.5 years) to diagnose PD or DLB. Compared to patients who phenoconverted to PD or DLB, onset of symptomatic neurogenic orthostatic hypotension in MSA patients occurred at a younger age ( $\approx 52$ years), with a shorter median time to diagnosis $(\approx 5$ years $)$ [27]. The presence of RBD and preserved olfaction in patients with PAF increased the probability of a future diagnosis of MSA, whereas olfactory loss increased the odds of developing PD/DLB [27]. These findings highlight the need for more research in identifying biomarkers that could be useful in aiding earlier diagnosis.

\section{Supine hypertension}

Supine hypertension occurs in $\sim 50 \%$ of patients with autonomic failure and orthostatic hypotension, as has been observed in MSA [101]. This may be a problem at night if such patients lie supine and horizontal as there is often a reversal of the circadian change in blood pressure [102]. A recent study also described the occurrence of abnormal circadian BP rhythm (absent nocturnal fall or a reversed nocturnal fall of blood pressure) in about half of the patients with PD. However, this feature and a reversed nocturnal circadian blood pressure rhythm was found to be much more common in MSA compared to idiopathic PD. This finding suggests that autonomic dysfunction plays an important contributing role in the control of circadian BP rhythms [103].

\section{Postprandial hypotension (PPH)}

Food ingestion can lower systemic blood pressure in MSA but not in healthy individuals, who have normal compensatory cardiac and regional haemodynamic responses. PPH is also an important feature of autonomic failure in patients with MSA [104]. PPH is present in both MSA-P and MSA$\mathrm{C}$, but the severity in MSA-C is greater than those with MSA-P [105]. PPH is also common in PD, even in those without other features of autonomic failure [106].

\section{Exercise-induced hypotension}

Exercise-induced hypotension has been reported in MSA [107]. An increase in sympathetic activity to the vasculature of non-exercising muscles and the other organs plays a major role in maintaining blood pressure. The consequences of exercise-induced hypotension can occur at various stages of exercise. Exercise-induced hypotension in those with MSA-C has been found to be greater than those with MSA-P in the supine position, but this does not get worse when the MSA-C patient is in the orthostatic position [108].

\section{Bladder dysfunction in MSA}

A recent study showed that $18.2 \%$ of MSA patients presented with bladder dysfunction as the initial manifestation, on average 2.8 years before any motor manifestation [109]. In men, urinary symptoms are typically preceded by erectile dysfunction. Bladder dysfunction, particularly urinary retention in MSA, may reflect pathology in the sacral spinal cord, a common site for MSA pathology. These findings are important especially for patient care. Surgical treatment of bladder outlet obstruction should be avoided, as it often fails in MSA patients, whereas prostatic surgery is not contraindicated in patients with PD.

Three uro-neurological features are important in MSA. These include large post-void residual urine volumes of $>100 \mathrm{ml}$ without prostatic hyperplasia in men and without common neurologic conditions (lumbar spondylosis and diabetes) $[110,111]$, an open bladder neck during filling-phase 
videourodynamics $[112,113]$, which is not uncommon in stress-incontinent women, but is extremely rare in men, and a sphincter electromyography (EMG) abnormality — sphincter denervation [112]. These are explained by the neuronal cell loss in Onuf's nucleus (a group of anterior horn cells found in the sacral spinal cord), which seem to degenerate early in the course of MSA [114]. Electrophysiologically, this leads to prolonged polyphasic sphincteric motor unit potentials (MUPs) on anal sphincter EMG testing. Although sphincter EMG abnormalities are noted in some patients with PD, dementia with Lewy bodies, pure autonomic failure, and progressive supranuclear palsy, this test still has an important diagnostic value in MSA especially when viewed in the context of other clinical features and paraclinical investigations [112].

\section{Sleep disorders in MSA}

MSA patients often present with nighttime sleep problems including rapid eye movement (REM) sleep behavior disorder (RBD) [115], periodic limb movements (PLMs), restless legs syndrome (RLS), or RLS-like symptoms [116], and all lead to sleep fragmentation and decreased sleep efficiency. However, this aspect of MSA has only been investigated in small cohorts with even less data comparing the polysomnographic (PSG) parameters. [117]. One study showed similar nighttime problems and PSG results for both MSA-P and MSA-C patients, despite different lesion localization of the pathologic processes in the two MSA subtypes [117]. Polysomnographic studies reported that in MSA patients, the total sleep time and sleep efficiency is reduced and waking after sleep onset is increased [118].

Rapid eye movement sleep behavior disorder (RBD) is the most common sleep-related disorder in MSA [119] and may precede the development of parkinsonism by years [120]. RBD is characterized by vigorous and injurious behaviors related to vivid, action-filled, and violent dreams during nocturnal REM sleep and REM sleep without atonia (RWA) [121] as determined by a polysomnogram (PSG) [115]. In postmortem studies of patients with RBD, the most frequent finding is neurodegeneration with abnormal deposition of $\alpha$-synuclein in pontomedullary brainstem nuclei [77].

The prevalence of RBD, as determined by polysomnography, is very high (88\%) in MSA patients. RBD signs have been found to be present in about half of MSA patients before the onset of motor symptoms and are present equally in both in MSA-P (82\%) and MSA-C (83\%) patients [122], suggesting that RBD may represent a prodromal phase in MSA [123]. However, RBD is not restricted to the prodromal phase, as up to $30 \%$ of MSA patients developed RBD before, $7 \%$ at the same time, and $63 \%$ after the onset of motor symptoms of MSA [124]. Generally, patients with idiopathic RBD are predominantly male [115]. However, patients with MSA having RBD are not predominantly male [125], similar to that seen with PD patients and RBD [126].

Interestingly, motor control has been shown to be transiently improved during RBD in patients with MSA, as confirmed by video recordings. Up to $80 \%$ of patients exhibited improvement in their movements, speech, or facial expression during REM sleep compared to the awake state. The improvement was present even in the most affected patients. There was no difference in the percentage of REM-related motor improvement between patients who were affected with MSA-P or MSA-C. However, the rate of motor or vocal improvement during REM sleep was $30-60 \%$ greater in PD than in patients with MSA, except for hypomimia [124].

Usually, RBD symptoms in MSA patients exist for a limited period shortly before the onset of other neurological symptoms, but generally disappear within a few years of the onset of neurological symptoms. This is likely due to progressive degeneration of the neuronal structures in the brainstem responsible for the occurrence of RBD [125].

\section{Respiratory features in MSA}

Respiratory problems, including stridor, sleep-disordered breathing (e.g., obstructive sleep apnoea-OSA) and respiratory insufficiency, are known to occur in MSA [118]. Of these, stridor is part of the second consensus diagnostic criteria [3] and sleep apnea represents a major cause of death in MSA [127, 128]. Nocturnal stridor and obstructive sleep apnea are the most common sleep-related breathing disorders in MSA patients [129].

OSA affects between 15 and 37\% of MSA patients [118]; nocturnal stridor (a strained, high-pitched, harsh respiratory sound) varies from 13 to $69 \%$ [130]. In one study, stridor was more frequently detected in MSA-C than in MSA-P patients [118], but the opposite has also been seen [129]. Stridor is associated with a poor prognosis in MSA. It is unclear whether death results from the vocal-cord paralysis per se, central hypoventilation, or both [64].

The causes that lead to nocturnal stridor are related to upper airway obstruction, such as vocal-cord abductor paralysis; an impairment of the respiratory center, such as Cheyne-Stokes respiration; or an impaired hypoxemic ventilatory response [131]. Laryngeal electromyography in patients with MSA and autonomic failure has revealed the evidence of denervation of the posterior and interarytenoid cricoarytenoid and partial denervation in the cricopharyngeal sphincter, sometimes leading to respiratory obstruction requiring a tracheostomy.

Vocal-cord paralysis can also occur in MSA. A history of nighttime snoring is usually the first sign; importantly, this is not oropharyngeal snoring, but laryngeal stridor and video polysomnography can differentiate between the two by examining the respiratory phases, whether inspiratory, 
expiratory, or both [132]. Bilateral vocal-cord paresis frequently occurs in MSA and can sometimes lead to death. Patients with symptoms of airway obstruction need a tracheostomy to bypass the level of obstruction. These tracheostomies are rarely removed because of the progressive nature of the disease [133].

In some MSA cases, hypertonicity rather than paresis of the vocal cords has been described using direct electromyography [134]. During episodes of stridor, the cords adopt a paramedian position, best diagnosed by a combination of laryngeal electromyography with a response to botulinum toxin being used to distinguish hypertonicity from paralysis in some cases.

Patients with MSA have impaired ventilatory drive, with minimal-to-no chemosensitivity to hypoxia [137]; thus, they may be at a significantly higher risk of becoming hypoxic without any reflex capacity to compensate. In addition, patients with MSA often have disturbances of respiratory rhythm during sleep [138]. These may explain why patients with MSA may die of respiratory insufficiency despite tracheostomy [41]. Clearly, some MSA patients have central hypoventilation in addition to stridor, which can only be diagnosed during repeated sleep evaluations.

\section{Cognitive involvement in MSA}

Cognitive impairment is an integral part of MSA, although dementia is a non-supporting diagnostic feature [3, 137]. In autopsy-confirmed MSA, the prevalence rates of mild, moderate, and severe cognitive impairment have been reported to be $22 \%, 2 \%$, and $0.5 \%$, respectively $[137,138]$.

Executive dysfunction is a prominent cognitive problem in MSA, affecting up to half of the patients [139-141]. This includes problems with semantic and phonemic word list generation [142, 143], perseverative behavior [144], and diverse impairments of problem solving, response inhibition, flexibility, attention, and working memory $[142,144]$.

Memory disturbances not reaching a diagnosis of dementia were observed in up to $66 \%$ of MSA patients. They were characterized by impaired learning [141], immediate [[145] and delayed recall, [139-141] and less often, impaired recognition [139], visuospatial and constructional difficulties [140, 143, 145].

On average, it takes about 7 years from MSA diagnosis for clinically significant cognitive symptoms to develop [[35], but pathologically proven MSA cases with earlier cognitive impairment [146-148] have been reported. Among MSA patients surviving more than 8 years, almost half of them develop cognitive problems [139], suggesting that the cumulative prevalence of dementia in MSA would be similar to that of Parkinson's disease (PD), if the disease had a longer course [149, 150]. Furthermore, 14\% of MSA patients have been found to have severe cognitive impairment in the year before death [35] and exceptionally long-term MSA survivors showed dementia onset between 13.5 and 17 years from the onset of the disease [32].

Cognitive impairment in MSA is predicted by factors such as greater motor disability [139, 145, 151, 152], male gender, educated for less than 10 years and the presence of early cardiovascular dysautonomia [153].

Cognitive impairment and MSA clinical subtypes have produced controversial results [141, 143, 154] with some reports, suggesting that the MSA-P patients have more problems with visuospatial and constructional function, verbal fluency, and executive functions [143, 153], while the MSA-C patients were impaired only in visuospatial and constructional functions [153]. These data suggested a more severe and widespread impairment in MSA-P patients despite similar disease duration.

Furthermore, cognitive deficits in MSA-C have been linked to degeneration in cerebral cortex, the pontocerebellar system, and the disruption of cerebrocerebellar connections (cerebrocerebellar circuitry) $[155,156]$. Described as reciprocal cerebrocerebellar circuits [157], the so-called cerebellar cognitive affective syndrome was mainly observed in acute cerebellar diseases such as infarctions and tumors. This syndrome is characterized by executive dysfunction, impaired spatial cognition, including visuospatial disorganization, and impaired visuospatial memory. Deficients in visuospatial function in this cerebellar syndrome give support to the hypothesis of a cerebellar contribution cognitive impairment in MSA. However, other investigators failed to demonstrate the contribution of cerebellar dysfunction in the cognitive profile of MSA patients [155].

Progressive frontotemporal degeneration on neuroimaging [140, 158-161] and postmortem findings of neuronal loss, astrogliosis, and GCI accumulation in frontal and temporal regions of MSA patients with dementia, further point towards cognitive decline as a characteristic feature in some MSA patients [137].

Almost all MRI studies have shown that there is a characteristic pattern of prefrontal, frontal, temporal, and parietal cortical atrophy in MSA-P [161-164] and MSA-C [165-168], although some qualitative differences between subgroups have been reported [168]. The distribution of cortical atrophy is in line with the findings of hypometabolism on fluorodeoxyglucose (FDG) positron emission tomography (PET) in prefrontal and frontal [169, 170], temporal, and parietal regions in MSA-P [170] and in frontal and inferior parietal regions in MSA-C [171, 172]. In favor of the hypothesis that there is a primary subcortical deafferentation of cortical regions, a correlation between pontine, midbrain, and cerebellar atrophy and impairment in different cognitive domains as well as global cognition in MSA patients has been reported [160], supported by the observation of cerebellar hypoperfusion in association with visuospatial 
decline in MSA-C [143]. Conversely, prefrontal atrophy has been shown to correlate with overall memory scores in MSA as a group [154], and in addition, there is a correlation between dorsolateral prefrontal hypoperfusion and visuospatial impairment in both motor MSA subtypes and executive dysfunction in MSA-P, all of which supports a primary cortical pathology in this aspect of MSA symptomatology [143].

PET and neuropsychological examination in MSA patients with different disease duration found that patients with a shorter duration showed executive and verbal memory dysfunctions, while patients with longer duration had multiple-domain cognitive impairment, including visuospatial deficits [140].

\section{Emotional lability and depression in MSA}

Patients with MSA frequently report emotional lability, with short (sometimes only one or two minute) episodes of crying due to happiness, or sadness, in response to relatively minor environmental stimuli. Pathological laughter and crying (PLC) is a condition in which a patient with an underlying neurological disorder exhibits episodes of laughter or crying or both, without an apparent motivating stimulus or to a stimulus that would not have elicited such response in the past. This problem is characterized by a deficit in the regulation and coordination of emotional expression [173]. PCL can provoke restrictive life-style modifications and even lead to social isolation. Despite its high prevalence and quality of life implications, it remains surprisingly understudied, and in clinical settings, it is often unrecognized [174]. Several scales are available to identify and characterize PLC. Among these, the two most commonly used in clinical research studies are the Pathological Laughter and Crying Scale and the Center for Neurologic Study-Lability Scale [175].

Importantly, PLC and mood disorders may coexist in up to half of MSA patients [175]. The resolution of pathological laughing or crying seems to be independent of the changes in anxiety or aggression scores [175]. A previous study found that all patients with MSA who exhibited pathological laughter and/or crying also had depression [176].

$40-85 \%$ of patients with MSA display mild depression [141, 144, 153, 177-179], and 1/3 are moderately-toseverely depressed $[177,180]$. Anxiety is reported to affect about $37 \%$ of MSA patients [143, 181]. Both MSA motor subtypes are associated with high levels of depression and anxiety [141, 143, 154, 180,182], with some studies, suggesting that MSA-P patients are more depressed, while MSA-C subjects are more anxious [154, 182]

Psychosis in MSA has also reported in some cases and up to $9.5 \%$ of patients with MSA-P develop hallucinations [183].

\section{Other non-motor features in MSA}

Gastrointestinal symptoms are frequent complaints in MSA resulting from reduced gastrointestinal motility due to autonomic nervous system dysfunction with delay in gastric emptying [184] occurring at the early stages of the disease $[61,93]$. Constipation is a well-known feature of MSA and can predate the onset of typical motor symptoms. Constipation may be explained by prolonged colonic transit time in line with a reduction of phasic rectal contraction and abdominal strain in patients with MSA [185]. A change in bowel habits suggests autonomic involvement of the lower gut [186].

Other non-motor features include vasomotor failure with diminished sweating (hypohidrosis) [187] and pupillomotor abnormalities. Usually, visual acuity, colour vision, and visual fields remain unaffected [188]. Sweating disorders, mainly manifesting as widespread anhidrosis, frequently occur in patients with MSA [39, 189]. The postganglionic sympathetic sudomotor involvement is only partly responsible for sudomotor dysfunction and suggests the involvement of postganglionic fibres or sweat glands later in the disease course [76]. Widespread progressive anhidrosis is a more severe feature in MSA compared to that seen in PD and PSP [190, 191]. Pupil abnormalities are not commonly recognized as features of MSA, although these have occasionally been reported including in the original cases of Shy and Drager's patients [4]. Pupillary response to eye drops was recently proposed as a useful aid for distinguishing PD and MSA [192]. However, the pupillary measurement in these disorders needs further study to confirm the usefulness of these proposed diagnostic tests.

Autonomic dysfunction was initially believed to be solely associated with preganglionic abnormalities in the brainstem and spinal cord in MSA [39, 193]. However, evidence of postganglionic involvement has been reported by showing that up to $30 \%$ of MSA patients have reduced (123) I-metaiodobenzylguanidine (MIBG) uptake at all stages of disease [194]. Furthermore, sudomotor abnormalities including impairment at pre- and postganglionic sites may coexist, indicating a further progression over time and the involvement of postganglionic fibres or sweat glands later in the disease course [76].

\section{The premotor phase in MSA}

The prodromal non-motor phase of MSA often precedes the motor symptoms by several months to years. Reports of pathologically proven MSA cases in which no classic motor symptoms (cerebellar, parkinsonian, or pyramidal tract) developed during the disease course [195] emphasize the need to consider premotor symptoms in the early evolution 
of the disorder. Early symptoms in MSA are frequently autonomic in nature (in 73\%) [83]. In men, erectile failure typically occurs $4.2( \pm 2.6)$ years prior to diagnosis. After erectile failure, orthostatic hypotension-a consistent hallmark of MSA [191] — fatigue following exercise, urinary urgency or hesitancy, and violent dream enactment behavior consistent with REM behavioral sleep disorder, are the most frequent initial symptoms. For most patients, the onset of motor symptoms is 1 year after the onset of autonomic symptoms. Although challenging to interpret, these symptoms can provide a window of opportunity for disease-modifying interventions if recognized in time, therefore, raising a suspicion of MSA diagnosis.

The presence of autonomic failure, erectile dysfunction, urinary urgency, nocturia, sleep problems (RBD), postural dizziness, and respiratory disturbances at presentation, in the absence of ataxia and parkinsonism, should be regarded as suggestive of premotor MSA [196]. Up to half of patients later diagnosed with MSA initially were classified as having pure autonomic failure, as they did not exhibit motor symptoms at the first presentation to a doctor $[138,179]$.

A pattern is emerging in MSA; with non-motor symptoms preceding the classic motor features showing a distinctive pattern of early genitourinary dysfunction followed by orthostatic hypotension in association with sleep disorders such as RBD, sleep apnoea, excessive snoring, and stridor [196]. Above all, respiratory dysfunction is the most suggestive symptom of MSA in the presence of other premotor symptoms. At the same time, in the premotor phase, olfaction and cognition [197] remain relatively intact compared with other parkinsonian disorders (Fig. 1).

The diagnostic challenge in the premotor phase of MSA is the substantial overlap with the non-motor symptoms of other neurodegenerative disorders, in particular Parkinson's

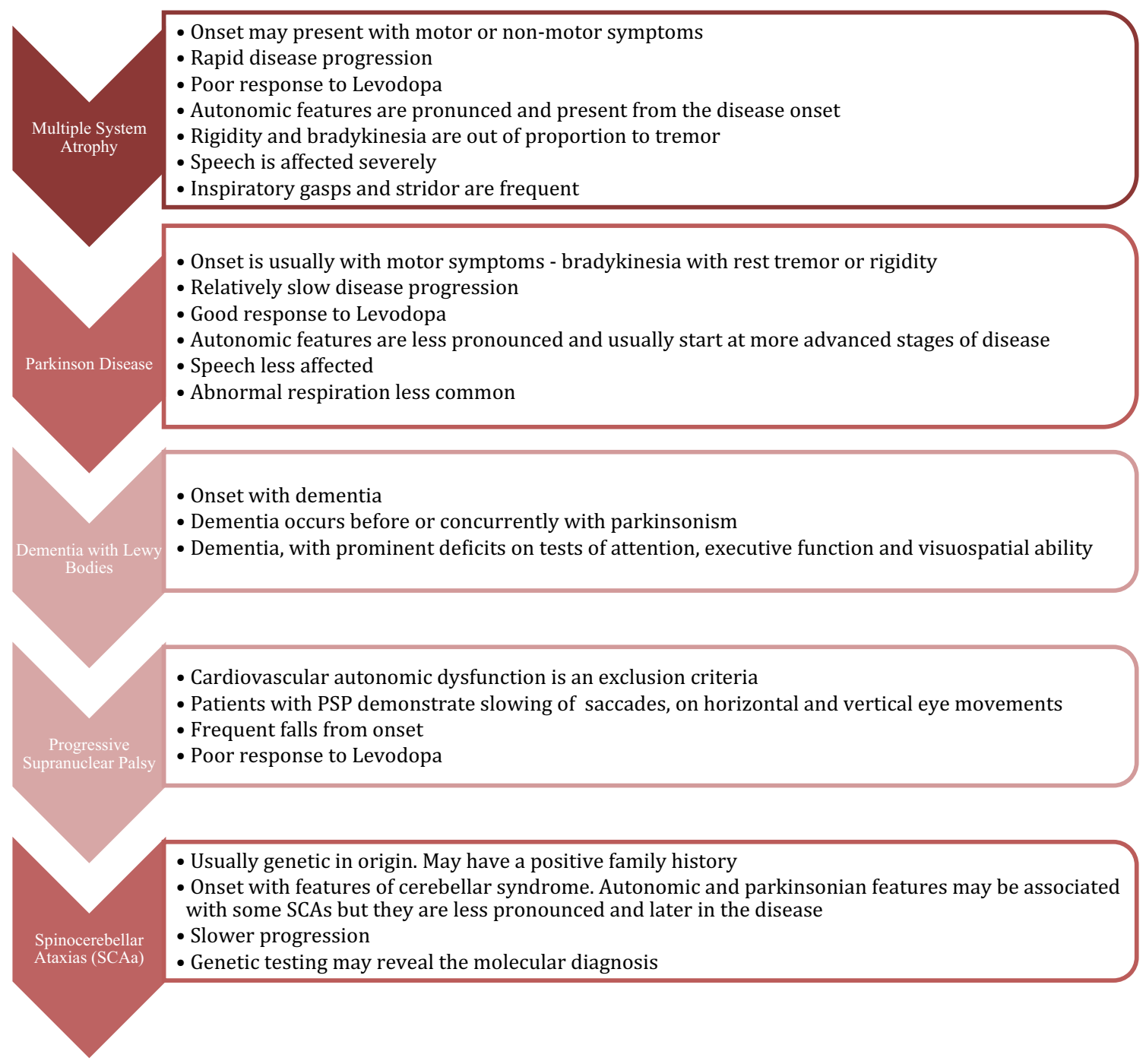

Fig. 1 Differential diagnosis in MSA 
disease and pure autonomic failure. However, at the time of diagnosis, autonomic dysfunction in MSA is typically more severe compared to that in PD and autonomic dysfunction preceding the development of parkinsonism supports MSA as a more likely diagnosis [138]. Conversely, a case with parkinsonism or cerebellar ataxia in the absence of erectile dysfunction or autonomic failure would make an MSA diagnosis less likely [83].

The spectrum of premotor symptoms of MSA is broad (Fig. 2) and should, therefore, be investigated more vigorously to achieve an early diagnosis of this serious illness and to avoid unnecessary therapeutic interventions [196].

\section{Treatment of non-motor symptoms in MSA}

Symptomatic treatment remains the current standard of care in MSA. Management strategies are focused on symptom control with medication for parkinsonism, autonomic lability, bladder and bowel dysfunction, and mood problems
[198] (Table 3). Deep brain stimulation is not recommended for MSA [199].

New strategies targeting $\alpha$-synuclein are in progress $[54,200]$. Unfortunately, most clinical trials have failed to show positive results due in part to the small number of enrolled patients, the inevitable accidental recruitment of non-MSA patients, and the relatively late intervention for disease-modifying treatments [201]. The only clinical trial showing positive results was intra-arterial and intravenous injection of autologous mesenchymal stem cells (MSCs), which delayed disease progression as measured by the unified MSA rating scale in patients with MSA-C [202]. Targeting the 'prion-like' cell-to-cell propagation of $\alpha$-synuclein using an $\alpha$-synuclein immunotherapy is an appealing approach and has been studied in animal models of MSA [203]. A combination of a single-chain antibody (CD5-D5) and anti-inflammatory treatment (lenalidomide) ameliorated gliosis, $\alpha$-synuclein accumulation, and behavioral deficits in MBP- $\alpha$-synuclein transgenic mice [204].

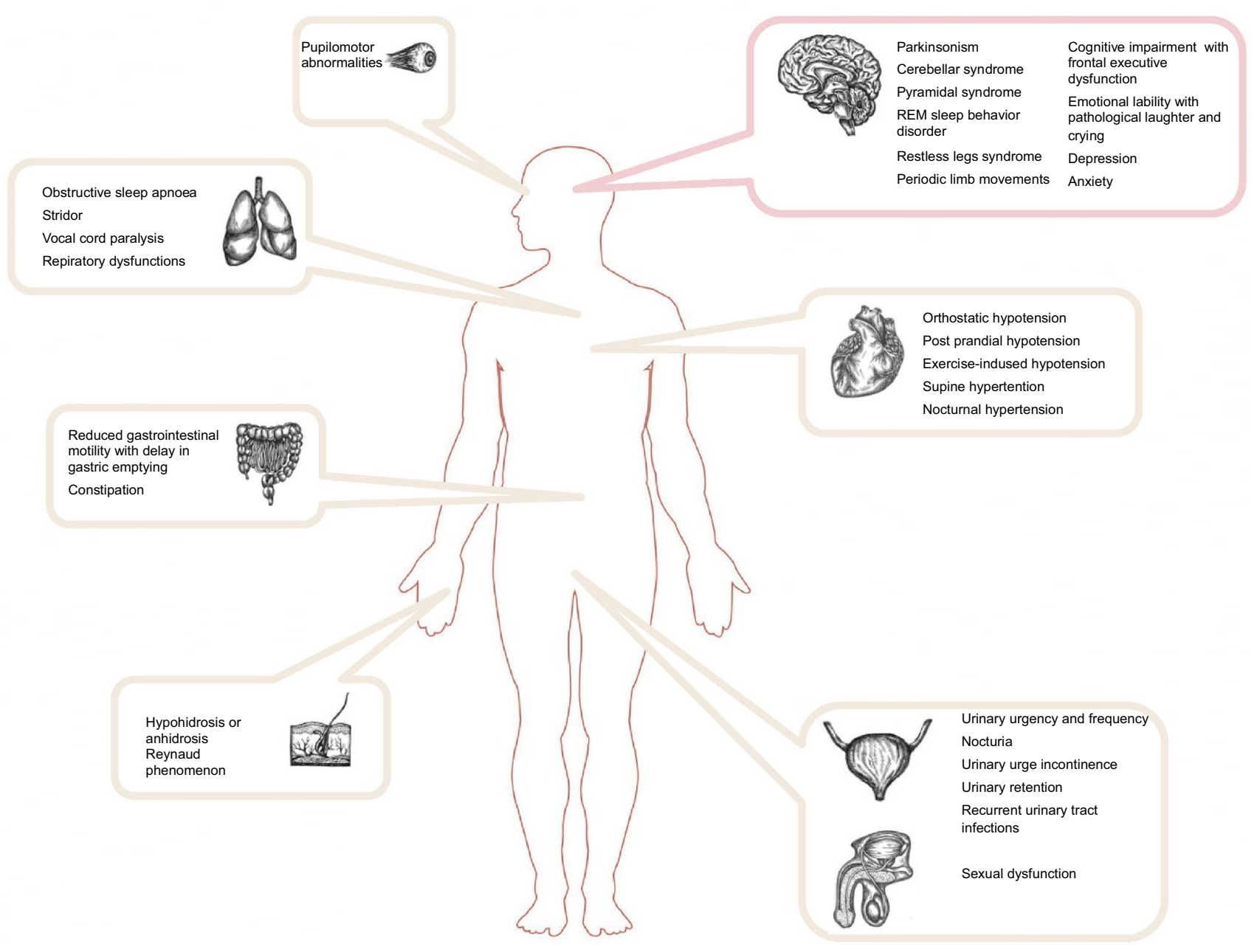

Fig. 2 Clinical spectrum of multi-organ involvement in multiple system atrophy 
Table 3 Symptomatic treatment in MSA

\begin{tabular}{|c|c|c|}
\hline Symptoms & Pharmacological treatment & Nonpharmacological treatment \\
\hline \multicolumn{3}{|l|}{ Non-motor symptoms } \\
\hline $\begin{array}{l}\text { Orthostatic hypotension } \\
\text { Postprandial hypotension } \\
\text { Supine hypertension }\end{array}$ & $\begin{array}{l}\text { Ephedrine } \\
\text { Fludrocortisone (needs to be avoided if patient also } \\
\text { has supine hypertension) } \\
\text { Midodrine } \\
\text { L-threo-DOPS } \\
\text { Octreotide } \\
\text { Atomoxetine (avoid before bedtime) } \\
\text { Droxidopa } \\
\text { Nebivolol } \\
\text { Clonidine } \\
\text { Sildenafil at bedtime } \\
\text { Nitroglycerine patch at bedtime } \\
\text { Losartan } \\
\text { Eplerenone } \\
\text { Nifedipine } \\
\text { Avoid before bedtime-non-steroidal anti-inflamma- } \\
\text { tory drugs (ibuprofen and indomethacin), norepi- } \\
\text { nephrine transporter inhibitors (atomoxetine) }\end{array}$ & $\begin{array}{l}\text { Elastic stockings } \\
\text { Adequate and higher salt and fluid intake } \\
\text { Head-up tilt during the night } \\
\text { Smaller but more frequent meals } \\
\text { Special set of exercises } \\
\text { Limit drinking water } 60-90 \text { min. before bedtime } \\
\text { Tilt the whole bed head-up by approximately } 10-20^{\circ} \text {, } \\
\text { in patient not tolerating this measure tilt only head } \\
\text { of the bed up to } 30^{\circ} \\
\text { Carbohydrate-rich snack at bedtime }\end{array}$ \\
\hline $\begin{array}{l}\text { Urinary dysfunction } \\
\text { Urinary incontinence } \\
\text { Incomplete bladder emptying } \\
\text { Nocturia }\end{array}$ & $\begin{array}{l}\text { Oxybutynin } \\
\text { Injections of Botulinum toxin A into the detrusor } \\
\text { muscle } \\
\text { Moxisylyte } \\
\text { Prazosin } \\
\text { Desmopressin intranasal spray }\end{array}$ & $\begin{array}{l}\text { Intermittent or permanent urethral or suprapu- } \\
\text { bic catheterization if post-void residual volume } \\
\text { is }>100 \mathrm{ml}\end{array}$ \\
\hline Erectile dysfunction & Sildenafil & \\
\hline $\begin{array}{l}\text { Neuropsychiatric manifestations } \\
\text { Depression }\end{array}$ & Selective Serotonin Reuptake Inhibitors (SSRIs) & Psychotherapy \\
\hline $\begin{array}{l}\text { Sleep disorders } \\
\text { REM-sleep behavior disorder }\end{array}$ & $\begin{array}{l}\text { Clonazepam } \\
\text { Melatonin } \\
\text { Gabapentin } \\
\text { Pregabalin } \\
\text { Sodium oxybate } \\
\text { Zopiclone } \\
\text { Temazepam }\end{array}$ & \\
\hline $\begin{array}{l}\text { Nocturnal stridor } \\
\text { Breathing problems }\end{array}$ & & $\begin{array}{l}\text { Non-invasive positive pressure ventilation (NPPV) } \\
\text { Continuous positive airway pressure (CPAP) } \\
\text { Tracheostomy }\end{array}$ \\
\hline \multicolumn{3}{|l|}{ Motor symptoms } \\
\hline $\begin{array}{l}\text { Parkinsonism } \\
\text { Cerebellar ataxia } \\
\text { Dystonia }\end{array}$ & $\begin{array}{l}\text { Levodopa } \\
\text { Amantadine } \\
\text { Botulinum toxin A }\end{array}$ & $\begin{array}{l}\text { Physiotherapy } \\
\text { Occupational therapy } \\
\text { Speech therapy } \\
\text { Physiotherapy } \\
\text { Occupational therapy } \\
\text { Speech therapy }\end{array}$ \\
\hline
\end{tabular}

Adapted from [198, 209, 210]

\section{Conclusion}

The clinical spectrum of MSA and, especially, the nonmotor features at disease onset represent a growing challenge for clinicians, researchers, and drug trials. Besides the current diagnostic criteria, several MSA subtypes, not fully fitting the currently used diagnostic criteria, are emerging, highlighting the complexity of the disease as well as the need for revised diagnostic tools. The ability to make an earlier diagnosis and thus intervention in MSA may lead to an increased quality of life, a better prognosis, as well as a greater chance of finding disease-modifying drugs.

Acknowledgements This study was supported by the MSA Trust, Medical Research Council (MRC UK MR/J004758/1, G0802760, G1001253). The Wellcome Trust equipment and strategic awards (Synaptopathies) (WT093205MA and WT104033/Z/14/Z). Dr. Viorica Chelban is supported by the Association of British Neurologists/MSA Trust Clinical Research Training Fellowship (F84 ABN 540868). 
Author contributions VC: conception, organization, execution, and manuscript preparation. DA: execution and writing of the first draft. DC: execution and writing of the first draft. AG: execution and writing of the first draft; EK: execution and writing of the first draft; VI: execution and writing of the first draft. $\mathrm{HH}$ : review and critique. SG: review and critique.

\section{Compliance with ethical standards}

Conflicts of interest Viorica Chelban-none, Daniela Aftene-none, Daniela Cateriniuc-none, Alexandru Gasnas-none, Ekawat Vichayanrat-none, Valeria Iodice- none, Stanislav Groppa—none, and Henry Houlden-none.

Open Access This article is licensed under a Creative Commons Attribution 4.0 International License, which permits use, sharing, adaptation, distribution and reproduction in any medium or format, as long as you give appropriate credit to the original author(s) and the source, provide a link to the Creative Commons licence, and indicate if changes were made. The images or other third party material in this article are included in the article's Creative Commons licence, unless indicated otherwise in a credit line to the material. If material is not included in the article's Creative Commons licence and your intended use is not permitted by statutory regulation or exceeds the permitted use, you will need to obtain permission directly from the copyright holder. To view a copy of this licence, visit http://creativecommons.org/licenses/by/4.0/.

\section{References}

1. Komatsu H, Kato M, Kinpara T, Ono T, Kakuto Y (2018) Possible multiple system atrophy with predominant parkinsonism in a patient with chronic schizophrenia: a case report. BMC Psychiatry 18:141

2. Fanciulli A, Wenning GK (2015) Multiple-system atrophy. N Engl J Med 372:249-263

3. Gilman $\mathrm{S}$ et al (2008) Second consensus statement on the diagnosis of multiple system atrophy. Neurology 71:670-676

4. Shy GM, Drager GA (1960) A neurological syndrome associated with orthostatic hypotension: a clinical-pathologic study. Arch Neurol 2:511-527

5. Graham JG, Oppenheimer DR (1969) Orthostatic hypotension and nicotine sensitivity in a case of multiple system atrophy. $\mathrm{J}$ Neurol Neurosurg Psychiatry 32:28-34

6. Papp MI, Kahn JE, Lantos PL (1989) Glial cytoplasmic inclusions in the CNS of patients with multiple system atrophy (striatonigral degeneration, olivopontocerebellar atrophy and Shy-Drager syndrome). J Neurol Sci 94:79-100

7. Jellinger KA, Wenning GK (2016) Multiple system atrophy: pathogenic mechanisms and biomarkers. J Neural Transm (Vienna) 123:555-572

8. Goedert M, Jakes R, Spillantini MG (2017) The synucleinopathies: twenty years on. J Parkinsons Dis 7:S51-s69

9. Goedert M, Masuda-Suzukake M, Falcon B (2017) Like prions: the propagation of aggregated tau and alpha-synuclein in neurodegeneration. Brain 140:266-278

10. Ubhi K et al (2014) Widespread microRNA dysregulation in multiple system atrophy-disease-related alteration in miR-96. Eur J Neurosci 39:1026-1041

11. Bleasel JM, Wong JH, Halliday GM, Kim WS (2014) Lipid dysfunction and pathogenesis of multiple system atrophy. Acta Neuropathol Commun 2:15
12. Don AS et al (2014) Altered lipid levels provide evidence for myelin dysfunction in multiple system atrophy. Acta Neuropathol Commun 2:150

13. Chen Y et al (2015) Analysis and meta-analysis of five polymorphisms of the LINGO1 and LINGO2 genes in Parkinson's disease and multiple system atrophy in a Chinese population. J Neurol 262:2478-2483

14. Stefanova N et al (2007) Microglial activation mediates neurodegeneration related to oligodendroglial alpha-synucleinopathy: implications for multiple system atrophy. Mov Disord 22:2196-2203

15. Halliday GM (2015) Re-evaluating the glio-centric view of multiple system atrophy by highlighting the neuronal involvement. Brain 138:2116-2119

16. Miki $\mathrm{Y}$ et al (2018) AMBRA1, a novel alpha-synuclein-binding protein, is implicated in the pathogenesis of multiple system atrophy. Brain Pathol 28:28-42

17. Jellinger KA (2014) Neuropathology of multiple system atrophy: new thoughts about pathogenesis. Mov Disord 29:1720-1741

18. Rath A et al (2012) Representation of rare diseases in health information systems: the Orphanet approach to serve a wide range of end users. Hum Mutat 33:803-808

19. Vanacore N (2005) Epidemiological evidence on multiple system atrophy. J Neural Transm (Vienna) 112:1605-1612

20. Bjornsdottir A, Gudmundsson G, Blondal H, Olafsson E (2013) Incidence and prevalence of multiple system atrophy: a nationwide study in Iceland. J Neurol Neurosurg Psychiatry $84: 136-140$

21. Chrysostome V et al (2004) Epidemiology of multiple system atrophy: a prevalence and pilot risk factor study in Aquitaine, France. Neuroepidemiology 23:201-208

22. Schrag A, Ben-Shlomo Y, Quinn NP (1999) Prevalence of progressive supranuclear palsy and multiple system atrophy: a crosssectional study. Lancet 354:1771-1775

23. Stefanova N, Bucke P, Duerr S, Wenning GK (2009) Multiple system atrophy: an update. Lancet Neurol 8:1172-1178

24. Tison F, Yekhlef F, Chrysostome V, Sourgen C (2000) Prevalence of multiple system atrophy. Lancet 355:495-496

25. Kaufmann H (1996) Consensus statement on the definition of orthostatic hypotension, pure autonomic failure and multiple system atrophy. Clin Auton Res 6:125-126

26. Singer $\mathrm{W}$ et al (2017) Pure autonomic failure: predictors of conversion to clinical CNS involvement. Neurology 88:1129-1136

27. Kaufmann $\mathrm{H}$ et al (2017) Natural history of pure autonomic failure: a United States prospective cohort. Ann Neurol 81:287-297

28. Koga $S$ et al (2015) When DLB, PD, and PSP masquerade as MSA: an autopsy study of 134 patients. Neurology 85:404-412

29. Wenning GK et al (2013) The natural history of multiple system atrophy: a prospective European cohort study. Lancet Neurol $12: 264-274$

30. Watanabe $\mathrm{H}$ et al (2002) Progression and prognosis in multiple system atrophy: an analysis of 230 Japanese patients. Brain 125:1070-1083

31. Klockgether T et al (1998) The natural history of degenerative ataxia: a retrospective study in 466 patients. Brain $121(\mathrm{Pt}$ 4):589-600

32. Petrovic IN et al (2012) Multiple system atrophy-parkinsonism with slow progression and prolonged survival: a diagnostic catch. Mov Disord 27:1186-1190

33. Wakabayashi K et al (2005) An autopsy case of early ("minimal change") olivopontocerebellar atrophy (multiple system atrophycerebellar). Acta Neuropathol 110:185-190

34. Ben-Shlomo Y, Wenning GK, Tison F, Quinn NP (1997) Survival of patients with pathologically proven multiple system atrophy: a meta-analysis. Neurology 48:384-393 
35. O'Sullivan SS et al (2008) Clinical outcomes of progressive supranuclear palsy and multiple system atrophy. Brain 131:1362-1372

36. Roncevic D et al (2014) Cerebellar and parkinsonian phenotypes in multiple system atrophy: similarities, differences and survival. J Neural Transm (Vienna) 121:507-512

37. Fanciulli A et al (2013) The potential prognostic role of cardiovascular autonomic failure in alpha-synucleinopathies. Eur $\mathbf{J}$ Neurol 20:231-235

38. Figueroa JJ et al (2014) Multiple system atrophy: prognostic indicators of survival. Mov Disord 29:1151-1157

39. Iodice $\mathrm{V}$ et al (2012) Autopsy confirmed multiple system atrophy cases: Mayo experience and role of autonomic function tests. J Neurol Neurosurg Psychiatry 83:453-459

40. Silber MH, Levine S (2000) Stridor and death in multiple system atrophy. Mov Disord 15:699-704

41. Jellinger KA, Lantos PL (2010) Papp-Lantos inclusions and the pathogenesis of multiple system atrophy: an update. Acta Neuropathol 119:657-667

42. VanderHorst VG et al (2015) alpha-Synuclein pathology accumulates in sacral spinal visceral sensory pathways. Ann Neurol 78:142-149

43. Kuzdas-Wood D et al (2015) Involvement of peripheral nerves in the transgenic PLP-alpha-syn model of multiple system atrophy: extending the phenotype. PLoS ONE 10:e0136575

44. Monzio Compagnoni G, Di Fonzo A (2019) Understanding the pathogenesis of multiple system atrophy: state of the art and future perspectives. Acta Neuropathol Commun 7:113

45. Hansen C et al (2011) alpha-Synuclein propagates from mouse brain to grafted dopaminergic neurons and seeds aggregation in cultured human cells. J Clin Invest 121:715-725

46. Luk KC et al (2012) Intracerebral inoculation of pathological alpha-synuclein initiates a rapidly progressive neurodegenerative alpha-synucleinopathy in mice. J Exp Med 209:975-986

47. Yamasaki TR et al (2019) Parkinson's disease and multiple system atrophy have distinct alpha-synuclein seed characteristics. J Biol Chem 294:1045-1058

48. Peelaerts W, Bousset L, Baekelandt V, Melki R (2018) a-Synuclein strains and seeding in Parkinson's disease, incidental Lewy body disease, dementia with Lewy bodies and multiple system atrophy: similarities and differences. Cell Tissue Res 373:195-212

49. Rey NL et al (2019) alpha-Synuclein conformational strains spread, seed and target neuronal cells differentially after injection into the olfactory bulb. Acta Neuropathol Commun 7:221

50. Peng $\mathrm{C}$ et al (2018) Cellular milieu imparts distinct pathological alpha-synuclein strains in alpha-synucleinopathies. Nature 557:558-563

51. Watanabe $\mathrm{H}$ et al (2016) Expanding concept of clinical conditions and symptoms in multiple system atrophy. Rinsho Shinkeigaku $=$ Clin Neurol 56:457-464

52. Ozawa T, Onodera O (2017) Multiple system atrophy: clinicopathological characteristics in Japanese patients. Proc Jpn Acad Ser B Phys Biol Sci 93:251-258

53. Low PA et al (2015) Natural history of multiple system atrophy in the USA: a prospective cohort study. Lancet Neurol 14:710-719

54. Krismer F, Wenning GK (2017) Multiple system atrophy: insights into a rare and debilitating movement disorder. Nat Rev Neurol 13:232-243

55. Batla A et al (2013) Markedly asymmetric presentation in multiple system atrophy. Parkinsonism Relat Disord 19:901-905

56. Kollensperger M et al (2008) Red flags for multiple system atrophy. Mov Disord 23:1093-1099

57. (1996) Consensus statement on the definition of orthostatic hypotension, pure autonomic failure, and multiple system atrophy. The Consensus Committee of the American Autonomic Society and the American Academy of Neurology. Neurology 46:1470. https://doi.org/10.1212/wnl.46.5.1470

58. Hwang J et al (2019) Spinal cord alpha-synuclein deposition associated with myoclonus in patients with MSA-C. Neurology 93:302-309

59. Quinn N (1989) Multiple system atrophy - the nature of the beast. J Neurol Neurosurg Psychiatry 52(Suppl):78-89

60. Xie $\mathrm{T}$ et al (2015) Comparison of clinical features in pathologically confirmed PSP and MSA patients followed at a tertiary center. NPJ Parkinsons Dis 1:15007

61. Colosimo C (2011) Nonmotor presentations of multiple system atrophy. Nat Rev Neurol 7:295-298

62. Spokes EG, Bannister R, Oppenheimer DR (1979) Multiple system atrophy with autonomic failure: clinical, histological and neurochemical observations on four cases. J Neurol Sci 43:59-82

63. Benarroch EE, Schmeichel AM, Low PA, Sandroni P, Parisi JE (2008) Loss of A5 noradrenergic neurons in multiple system atrophy. Acta Neuropathol 115:629-634

64. Glass GA, Josephs KA, Ahlskog JE (2006) Respiratory insufficiency as the primary presenting symptom of multiple-system atrophy. Arch Neurol 63:978-981

65. Benarroch EE (2005) Paraventricular nucleus, stress response, and cardiovascular disease. Clin Auton Res 15:254-263

66. Guyenet PG (2006) The sympathetic control of blood pressure. Nat Rev Neurosci 7:335-346

67. Deguchi K et al (2004) Abnormal baroreceptor-mediated vasopressin release as possible marker in early diagnosis of multiple system atrophy. J Neurol Neurosurg Psychiatry 75:110-115

68. Mishima $\mathrm{T}$ et al (2017) Reduced orexin immunoreactivity in Perry syndrome and multiple system atrophy. Parkinsonism Relat Disord 42:85-89

69. Benarroch EE et al (2009) Dopamine cell loss in the periaqueductal gray in multiple system atrophy and Lewy body dementia. Neurology 73:106-112

70. Christopher L et al (2015) Salience network and parahippocampal dopamine dysfunction in memory-impaired Parkinson disease. Ann Neurol 77:269-280

71. Woods CG (2016) Autonomic neurology. Eur J Hum Genet 24:152

72. Benarroch EE, Schmeichel AM, Parisi JE (2001) Depletion of cholinergic neurons of the medullary arcuate nucleus in multiple system atrophy. Auton Neurosci 87:293-299

73. Benarroch EE, Schmeichel AM, Low PA, Parisi JE (2003) Depletion of ventromedullary NK-1 receptor-immunoreactive neurons in multiple system atrophy. Brain 126:2183-2190

74. Presti MF, Schmeichel AM, Low PA, Parisi JE, Benarroch EE (2014) Degeneration of brainstem respiratory neurons in dementia with Lewy bodies. Sleep 37:373-378

75. Benarroch EE (2013) Pedunculopontine nucleus: functional organization and clinical implications. Neurology 80:1148-1155

76. Coon EA et al (2017) Anhidrosis in multiple system atrophy involves pre- and postganglionic sudomotor dysfunction. Mov Disord 32:397-404

77. Boeve BF et al (2007) Pathophysiology of REM sleep behaviour disorder and relevance to neurodegenerative disease. Brain 130:2770-2788

78. Lu J, Sherman D, Devor M, Saper CB (2006) A putative flip-flop switch for control of REM sleep. Nature 441:589-594

79. St Louis EK et al (2014) Lesional REM sleep behavior disorder localizes to the dorsomedial pons. Neurology 83:1871-1873

80. Schmeichel AM et al (2008) Mesopontine cholinergic neuron involvement in Lewy body dementia and multiple system atrophy. Neurology 70:368-373

81. Orimo $S$ et al (2007) Degeneration of cardiac sympathetic nerve can occur in multiple system atrophy. Acta Neuropathol $113: 81-86$ 
82. Kennedy PG, Duchen LW (1985) A quantitative study of intermediolateral column cells in motor neuron disease and the ShyDrager syndrome. J Neurol Neurosurg Psychiatry 48:1103-1106

83. McKay JH, Cheshire WP (2018) First symptoms in multiple system atrophy. Clin Auton Res 28:215-221

84. Gilman S et al (1999) Consensus statement on the diagnosis of multiple system atrophy. J Neurol Sci 163:94-98

85. Tandon R, Pradhan S (2015) Autonomic predominant multiple system atrophy in the context of Parkinsonian and cerebellar variants. Clin Neurol Neurosurg 130:110-113

86. Pavy-Le Traon A et al (2016) New insights into orthostatic hypotension in multiple system atrophy: a European multicentre cohort study. J Neurol Neurosurg Psychiatry 87:554-561

87. Sun $\mathrm{Z}$ et al (2016) Prediction of orthostatic hypotension in multiple system atrophy and Parkinson disease. Sci Rep 6:21649

88. Kuzdas D et al (2013) Oligodendroglial alpha-synucleinopathy and MSA-like cardiovascular autonomic failure: experimental evidence. Exp Neurol 247:531-536

89. Mathias CJ, Mallipeddi R, Bleasdale-Barr K (1999) Symptoms associated with orthostatic hypotension in pure autonomic failure and multiple system atrophy. J Neurol 246:893-898

90. Hague K, Lento P, Morgello S, Caro S, Kaufmann H (1997) The distribution of Lewy bodies in pure autonomic failure: autopsy findings and review of the literature. Acta Neuropathol 94:192-196

91. Kaufmann H, Hague K, Perl D (2001) Accumulation of alphasynuclein in autonomic nerves in pure autonomic failure. Neurology 56:980-981

92. Sakakibara R, Hattori T, Uchiyama T, Asahina M, Yamanishi $\mathrm{T}$ (2000) Micturitional disturbance in pure autonomic failure. Neurology 54:499-501

93. Mabuchi $\mathrm{N}$ et al (2005) Progression and prognosis in pure autonomic failure (PAF): comparison with multiple system atrophy. J Neurol Neurosurg Psychiatry 76:947-952

94. Arai K, Kato N, Kashiwado K, Hattori T (2000) Pure autonomic failure in association with human alpha-synucleinopathy. Neurosci Lett 296:171-173

95. Kaufmann H, Goldstein DS (2010) Pure autonomic failure: a restricted Lewy body synucleinopathy or early Parkinson disease? Neurology 74:536-537

96. Silveira-Moriyama L et al (2009) Hyposmia in pure autonomic failure. Neurology 72:1677-1681

97. Hirayama $\mathrm{M}$ et al (1995) A scintigraphical qualitative analysis of peripheral vascular sympathetic function with meta-[123I] iodobenzylguanidine in neurological patients with autonomic failure. J Auton Nerv Syst 53:230-234

98. Ikemura $\mathrm{M}$ et al (2008) Lewy body pathology involves cutaneous nerves. J Neuropathol Exp Neurol 67:945-953

99. Shishido $\mathrm{T}$ et al (2010) alpha-synuclein accumulation in skin nerve fibers revealed by skin biopsy in pure autonomic failure. Neurology 74:608-610

100. Muppidi S, Miglis MG (2017) Is pure autonomic failure an early marker for Parkinson disease, dementia with Lewy bodies, and multiple system atrophy? And other updates on recent autonomic research. Clin Auton Res 27:71-73

101. Mann S et al (1984) Supine hypertension, blood pressure variability and circadian rhythm in autonomic failure: the role of ambulatory intra-arterial monitoring. Clin Exp Pharmacol Physiol 11:347-350

102. Vichayanrat E et al (2017) Twenty-four-hour ambulatory blood pressure and heart rate profiles in diagnosing orthostatic hypotension in Parkinson's disease and multiple system atrophy. Eur J Neurol 24:90-97

103. Fanciulli A et al (2016) Supine hypertension in Parkinson's disease and multiple system atrophy. Clin Auton Res 26:97-105
104. Mathias CJ et al (1989) Cardiovascular, biochemical and hormonal changes during food-induced hypotension in chronic autonomic failure. J Neurol Sci 94:255-269

105. Smith GD, Von Der Thusen J, Mathias CJ (1998) Comparison of the blood pressure response to food in two clinical subgroups of multiple system atrophy (Shy-Drager syndrome). Parkinsonism Relat Disord 4:113-117

106. Chaudhuri KR et al (1997) Postprandial hypotension and parkinsonian state in Parkinson's disease. Mov Disord 12:877-884

107. Smith GD, Mathias CJ (1995) Postural hypotension enhanced by exercise in patients with chronic autonomic failure. QJM $88: 251-256$

108. Smith GD, Mathias CJ (1996) Differences in cardiovascular responses to supine exercise and to standing after exercise in two clinical subgroups of Shy-Drager syndrome (multiple system atrophy). J Neurol Neurosurg Psychiatry 61:297-303

109. Sakakibara R et al (2019) Bladder dysfunction as the initial presentation of multiple system atrophy: a prospective cohort study. Clin Auton Res 29:627-631

110. Yamamoto T et al (2017) The utility of post-void residual volume versus sphincter electromyography to distinguish between multiple system atrophy and Parkinson's disease. PLoS ONE 12:e0169405

111. Yamamoto T et al (2005) When is Onuf's nucleus involved in multiple system atrophy? A sphincter electromyography study. J Neurol Neurosurg Psychiatry 76:1645-1648

112. Sakakibara R, Tateno F, Yamamoto T, Uchiyama T, Yamanishi T (2018) Urological dysfunction in synucleinopathies: epidemiology, pathophysiology and management. Clin Auton Res 28:83-101

113. Ogawa T et al (2017) Prevalence and treatment of LUTS in patients with Parkinson disease or multiple system atrophy. Nat Rev Urol 14:79-89

114. Coon EA, Cutsforth-Gregory JK, Benarroch EE (2018) Neuropathology of autonomic dysfunction in synucleinopathies. Mov Disord 33:349-358

115. American Academy of Sleep, M (2005) The international classification of sleep disorders: diagnostic \& coding manual. American Academy of Sleep Medicine, Westchester

116. Ferini-Strambi L (2007) RLS-like symptoms: differential diagnosis by history and clinical assessment. Sleep Med 8(Suppl 2):S3-6

117. Muntean ML, Sixel-Doring F, Trenkwalder C (2013) No difference in sleep and RBD between different types of patients with multiple system atrophy: a pilot video-polysomnographical study. Sleep Disord 2013:258390

118. Vetrugno R et al (2004) Sleep disorders in multiple system atrophy: a correlative video-polysomnographic study. Sleep Med $5: 21-30$

119. Vetrugno R et al (2009) Status dissociatus evolving from REM sleep behaviour disorder in multiple system atrophy. Sleep Med 10:247-252

120. Moreno-Lopez $\mathrm{C}$ et al (2011) Excessive daytime sleepiness in multiple system atrophy (SLEEMSA study). Arch Neurol 68:223-230

121. Schenck CH, Bundlie SR, Patterson AL, Mahowald MW (1987) Rapid eye movement sleep behavior disorder. A treatable parasomnia affecting older adults. JAMA 257:1786-1789

122. Palma JA et al (2015) Prevalence of REM sleep behavior disorder in multiple system atrophy: a multicenter study and metaanalysis. Clin Auton Res 25:69-75

123. Iranzo A et al (2014) Neuropathology of prodromal Lewy body disease. Mov Disord 29:410-415

124. De Cock VC et al (2011) The improvement of movement and speech during rapid eye movement sleep behaviour disorder in multiple system atrophy. Brain 134:856-862 
125. Nomura $T$ et al (2011) Comparison of the clinical features of rapid eye movement sleep behavior disorder in patients with Parkinson's disease and multiple system atrophy. Psychiatry Clin Neurosci 65:264-271

126. Lavault $\mathrm{S}$ et al (2010) Does clinical rapid eye movement behavior disorder predict worse outcomes in Parkinson's disease? J Neurol 257:1154-1159

127. Ohshima Y et al (2017) Natural course and potential prognostic factors for sleep-disordered breathing in multiple system atrophy. Sleep Med 34:13-17

128. Shimohata T et al (2016) Mechanisms and prevention of sudden death in multiple system atrophy. Parkinsonism Relat Disord 30:1-6

129. Ghorayeb I, Bioulac B, Tison F (2005) Sleep disorders in multiple system atrophy. J Neural Transm (Vienna) 112:1669-1675

130. Yamaguchi M, Arai K, Asahina M, Hattori T (2003) Laryngeal stridor in multiple system atrophy. Eur Neurol 49:154-159

131. Shimohata T et al (2007) Daytime hypoxemia, sleep-disordered breathing, and laryngopharyngeal findings in multiple system atrophy. Arch Neurol 64:856-861

132. Comabella M, Montalban X, Serena J, Lozano M, Codina A (1996) Early vocal cord paralysis in olivopontocerebellar atrophy. J Neurol 243:670-671

133. Blumin JH, Berke GS (2002) Bilateral vocal fold paresis and multiple system atrophy. Arch Otolaryngol Head Neck Surg 128:1404-1407

134. Merlo IM, Occhini A, Pacchetti C, Alfonsi E (2002) Not paralysis, but dystonia causes stridor in multiple system atrophy. Neurology 58:649-652

135. Tsuda T, Onodera H, Okabe S, Kikuchi Y, Itoyama Y (2002) Impaired chemosensitivity to hypoxia is a marker of multiple system atrophy. Ann Neurol 52:367-371

136. Munschauer FE, Loh L, Bannister R, Newsom-Davis J (1990) Abnormal respiration and sudden death during sleep in multiple system atrophy with autonomic failure. Neurology 40:677-679

137. Stankovic I et al (2014) Cognitive impairment in multiple system atrophy: a position statement by the Neuropsychology Task Force of the MDS Multiple System Atrophy (MODIMSA) study group. Mov Disord 29:857-867

138. Wenning GK, Ben Shlomo Y, Magalhaes M, Daniel SE, Quinn NP (1994) Clinical features and natural history of multiple system atrophy. An analysis of 100 cases. Brain 117(Pt 4):835-845

139. Brown RG et al (2010) Cognitive impairment in patients with multiple system atrophy and progressive supranuclear palsy. Brain 133:2382-2393

140. Lyoo CH et al (2008) Effects of disease duration on the clinical features and brain glucose metabolism in patients with mixed type multiple system atrophy. Brain 131:438-446

141. Siri C et al (2013) A cross-sectional multicenter study of cognitive and behavioural features in multiple system atrophy patients of the parkinsonian and cerebellar type. J Neural Transm (Vienna) 120:613-618

142. Dujardin K, Defebvre L, Krystkowiak P, Degreef JF, Destee A (2003) Executive function differences in multiple system atrophy and Parkinson's disease. Parkinsonism Relat Disord 9:205-211

143. Kawai $Y$ et al (2008) Cognitive impairments in multiple system atrophy: MSA-C vs MSA-P. Neurology 70:1390-1396

144. Kao AW et al (2009) Cognitive and neuropsychiatric profile of the synucleinopathies: Parkinson disease, dementia with Lewy bodies, and multiple system atrophy. Alzheimer Dis Assoc Disord 23:365-370

145. Kim HJ et al (2013) Clinical and imaging characteristics of dementia in multiple system atrophy. Parkinsonism Relat Disord 19:617-621

146. Konagaya M, Sakai M, Matsuoka Y, Konagaya Y, Hashizume Y (1999) Multiple system atrophy with remarkable frontal lobe atrophy. Acta Neuropathol 97:423-428
147. Wakabayashi K, Ikeuchi T, Ishikawa A, Takahashi H (1998) Multiple system atrophy with severe involvement of the motor cortical areas and cerebral white matter. J Neurol Sci 156:114-117

148. Kitayama M, Wada-Isoe K, Irizawa Y, Nakashima K (2009) Assessment of dementia in patients with multiple system atrophy. Eur J Neurol 16:589-594

149. Hely MA, Reid WG, Adena MA, Halliday GM, Morris JG (2008) The Sydney multicenter study of Parkinson's disease: the inevitability of dementia at 20 years. Mov Disord 23:837-844

150. de Lau LM, Schipper CM, Hofman A, Koudstaal PJ, Breteler MM (2005) Prognosis of Parkinson disease: risk of dementia and mortality: the Rotterdam Study. Arch Neurol 62:1265-1269

151. Kawamura $\mathrm{K}$ et al (2010) Factors influencing the cognitive function in patients with multiple system atrophy. Mov Disord 25:2891-2892

152. Kim HJ, Jeon BS (2012) Multiple system atrophy with prolonged survival. Mov Disord 27:1834

153. Stanzani-Maserati $M$ et al (2014) Cognitive and sleep features of multiple system atrophy: review and prospective study. Eur Neurol 72:349-359

154. Chang CC et al (2009) Cognitive deficits in multiple system atrophy correlate with frontal atrophy and disease duration. Eur J Neurol 16:1144-1150

155. Burk K, Daum I, Rub U (2006) Cognitive function in multiple system atrophy of the cerebellar type. Mov Disord 21:772-776

156. Hong HJ, Song SK, Lee PH, Sohn YH, Lee JE (2011) Cognitive impairments in multiple system atrophy of the cerebellar type. J Mov Disord 4:41-45

157. Schmahmann JD, Sherman JC (1998) The cerebellar cognitive affective syndrome. Brain 121(Pt 4):561-579

158. Horimoto $\mathrm{Y}$ et al (2000) Cerebral atrophy in multiple system atrophy by MRI. J Neurol Sci 173:109-112

159. Konagaya M, Konagaya Y, Sakai M, Matsuoka Y, Hashizume Y (2002) Progressive cerebral atrophy in multiple system atrophy. J Neurol Sci 195:123-127

160. Paviour DC, Price SL, Jahanshahi M, Lees AJ, Fox NC (2006) Longitudinal MRI in progressive supranuclear palsy and multiple system atrophy: rates and regions of atrophy. Brain 129:1040-1049

161. Brenneis $C$ et al (2007) Progression of brain atrophy in multiple system atrophy. A longitudinal VBM study. J Neurol 254:191-196

162. Brenneis C et al (2003) Voxel-based morphometry detects cortical atrophy in the Parkinson variant of multiple system atrophy. Mov Disord 18:1132-1138

163. Kaasinen V et al (2013) Brain glucose metabolism in neuropathologically confirmed multiple system atrophy. J Neurol 260:1922-1924

164. Minnerop M et al (2007) Voxel-based morphometry and voxelbased relaxometry in multiple system atrophy-a comparison between clinical subtypes and correlations with clinical parameters. Neuroimage 36:1086-1095

165. Specht K et al (2003) In vivo voxel-based morphometry in multiple system atrophy of the cerebellar type. Arch Neurol 60:1431-1435

166. Specht K, Minnerop M, Muller-Hubenthal J, Klockgether T (2005) Voxel-based analysis of multiple-system atrophy of cerebellar type: complementary results by combining voxelbased morphometry and voxel-based relaxometry. Neuroimage 25:287-293

167. Hauser TK et al (2006) Visualization and quantification of disease progression in multiple system atrophy. Mov Disord 21:1674-1681

168. Brenneis C et al (2006) Cortical atrophy in the cerebellar variant of multiple system atrophy: a voxel-based morphometry study. Mov Disord 21:159-165 
169. De Volder AG et al (1989) Decreased glucose utilization in the striatum and frontal lobe in probable striatonigral degeneration. Ann Neurol 26:239-247

170. Otsuka M et al (1996) Glucose metabolism in the cortical and subcortical brain structures in multiple system atrophy and Parkinson's disease: a positron emission tomographic study. J Neurol Sci 144:77-83

171. Lee PH, An YS, Yong SW, Yoon SN (2008) Cortical metabolic changes in the cerebellar variant of multiple system atrophy: a voxel-based FDG-PET study in 41 patients. Neuroimage 40:796-801

172. Gilman S et al (1994) Patterns of cerebral glucose metabolism detected with positron emission tomography differ in multiple system atrophy and olivopontocerebellar atrophy. Ann Neurol 36:166-175

173. Parvizi J et al (2006) Diagnosis and management of pathological laughter and crying. Mayo Clin Proc 81:1482-1486

174. Finegan E, Chipika RH, Shing SLH, Hardiman O, Bede P (2019) Pathological crying and laughing in motor neuron disease: pathobiology, screening, intervention. Front Neurol 10:260

175. Robinson RG, Parikh RM, Lipsey JR, Starkstein SE, Price TR (1993) Pathological laughing and crying following stroke: validation of a measurement scale and a double-blind treatment study. Am J Psychiatry 150:286-293

176. Parvizi J, Joseph J, Press DZ, Schmahmann JD (2007) Pathological laughter and crying in patients with multiple system atrophycerebellar type. Mov Disord 22:798-803

177. Gill CE, Khurana RK, Hibler RJ (1999) Occurrence of depressive symptoms in Shy-Drager syndrome. Clin Auton Res 9:1-4

178. Benrud-Larson LM, Sandroni P, Schrag A, Low PA (2005) Depressive symptoms and life satisfaction in patients with multiple system atrophy. Mov Disord 20:951-957

179. Kollensperger M et al (2010) Presentation, diagnosis, and management of multiple system atrophy in Europe: final analysis of the European multiple system atrophy registry. Mov Disord 25:2604-2612

180. Schrag A et al (2006) Health-related quality of life in multiple system atrophy. Mov Disord 21:809-815

181. Schrag A et al (2010) A comparison of depression, anxiety, and health status in patients with progressive supranuclear palsy and multiple system atrophy. Mov Disord 25:1077-1081

182. Balas M, Balash Y, Giladi N, Gurevich T (2010) Cognition in multiple system atrophy: neuropsychological profile and interaction with mood. J Neural Transm (Vienna) 117:369-375

183. Papapetropoulos S, Tuchman A, Laufer D, Mash DC (2007) Hallucinations in multiple system atrophy. Parkinsonism Relat Disord 13:193-194

184. Tanaka Y et al (2012) Is there delayed gastric emptying in patients with multiple system atrophy? An analysis using the (13)C-acetate breath test. J Neurol 259:1448-1452

185. Sakakibara R et al (2004) Colonic transit time, sphincter EMG, and rectoanal videomanometry in multiple system atrophy. Mov Disord 19:924-929

186. Mathias CJ (2006) Multiple system atrophy and autonomic failure. J Neural Transm Suppl. https://doi.org/10.1007/978-3-21145295-0_52.

187. Shindo K et al (2017) Vasomotor regulation in patients with multiple system atrophy. J Neural Transm (Vienna) 124:477-481

188. Armstrong RA (2014) Visual signs and symptoms of multiple system atrophy. Clin Exp Optom 97:483-491

189. Cohen J, Low P, Fealey R, Sheps S, Jiang NS (1987) Somatic and autonomic function in progressive autonomic failure and multiple system atrophy. Ann Neurol 22:692-699

190. Sandroni P, Ahlskog JE, Fealey RD, Low PA (1991) Autonomic involvement in extrapyramidal and cerebellar disorders. Clin Auton Res 1:147-155
191. Lipp A et al (2009) Prospective differentiation of multiple system atrophy from Parkinson disease, with and without autonomic failure. Arch Neurol 66:742-750

192. Yamashita F et al (2010) Pupillary autonomic dysfunction in multiple system atrophy and Parkinson's disease: an assessment by eye-drop tests. Clin Auton Res 20:191-197

193. Ozawa T (2007) Morphological substrate of autonomic failure and neurohormonal dysfunction in multiple system atrophy: impact on determining phenotype spectrum. Acta Neuropathol 114:201-211

194. Nagayama $\mathrm{H}$ et al (2010) Abnormal cardiac [(123)I]-meta-iodobenzylguanidine uptake in multiple system atrophy. Mov Disord 25:1744-1747

195. Gaig C et al (2008) Pathological description of a non-motor variant of multiple system atrophy. J Neurol Neurosurg Psychiatry 79:1399-1400

196. Jecmenica-Lukic M, Poewe W, Tolosa E, Wenning GK (2012) Premotor signs and symptoms of multiple system atrophy. Lancet Neurol 11:361-368

197. Wenning GK, Brown R (2009) Dementia in multiple system atrophy: does it exist? Eur J Neurol 16:551-552

198. Chelban VBC, Houlden H (2016) Updates on potential therapeutic targets in MSA. ACNR 15:8-11

199. Meissner WG et al (2016) Outcome of deep brain stimulation in slowly progressive multiple system atrophy: a clinico-pathological series and review of the literature. Parkinsonism Relat Disord 24:69-75

200. Schenk DB et al (2017) First-in-human assessment of PRX002, an anti-alpha-synuclein monoclonal antibody, in healthy volunteers. Mov Disord 32:211-218

201. Koga S, Dickson DW (2018) Recent advances in neuropathology, biomarkers and therapeutic approach of multiple system atrophy. J Neurol Neurosurg Psychiatry 89:175-184

202. Lee PH et al (2012) A randomized trial of mesenchymal stem cells in multiple system atrophy. Ann Neurol 72:32-40

203. Schneeberger A, Tierney L, Mandler M (2016) Active immunization therapies for Parkinson's disease and multiple system atrophy. Mov Disord 31:214-224

204. Valera E et al (2017) Combination of alpha-synuclein immunotherapy with anti-inflammatory treatment in a transgenic mouse model of multiple system atrophy. Acta Neuropathol Commun $5: 2$

205. Aoki $\mathrm{N}$ et al (2015) Atypical multiple system atrophy is a new subtype of frontotemporal lobar degeneration: frontotemporal lobar degeneration associated with alpha-synuclein. Acta Neuropathol 130:93-105

206. Masui K, Nakata Y, Fujii N, Iwaki T (2012) Extensive distribution of glial cytoplasmic inclusions in an autopsied case of multiple system atrophy with a prolonged 18 -year clinical course. Neuropathology 32:69-76

207. DelleDonne A et al (2008) Incidental Lewy body disease and preclinical Parkinson disease. Arch Neurol 65:1074-1080

208. Ling $\mathrm{H}$ et al (2015) Minimal change multiple system atrophy: an aggressive variant? Mov Disord 30:960-967

209. Rohrer G, Höglinger GU, Levin J (2018) Symptomatic therapy of multiple system atrophy. Autonomic Neurosci Basic Clin 211:26-30

210. Jordan J et al (2019) Management of supine hypertension in patients with neurogenic orthostatic hypotension: scientific statement of the American Autonomic Society, European Federation of Autonomic Societies, and the European Society of Hypertension. J Hypertens 37:1541-1546 